\title{
Effect of age on the endothelial cell count in the normal eye
}

\author{
R. S. WILSON AND M. J. ROPER-HALL \\ From the Birmingham and Midland Eye Hospital, Church Street, Birmingham B3 2NS
}

SUMMARY The endothelial cell count was studied in 275 normal eyes. It showed a gradual decline to the age of 50 but no appreciable difference thereafter. Review of earlier reports of progressive reduction throughout life indicates that a different interpretation is likely, which conforms with the results of this and other recent studies. The value of detailed endothelial studies is discussed briefly.

Corneal clarity is maintained by the endothelial layer possessing the ability to pump water out of the corneal stroma against an osmotic gradient. To perform this function the endothelial layer must consist of healthy cells above a minimum cell density. If the average cell count per square millimetre falls below 1000 , it is likely that stromal oedema and bullous keratopathy will ensue. This paper reports the effects of age on the endothelial cell density.

\section{Subjects and methods}

Two hundred and seventy-five eyes were photographed which showed no evidence of clinical disease and had not suffered any insult to the anterior segment in the form of accidental or surgical trauma. The patients were drawn from 2 main groups. The smaller and younger age groups were those patients who had had corneal injuries to the fellow eye, with no evidence of pathology in the eye studied; the second and larger group was of patients who were admitted to hospital for cataract extraction or who had had cataract surgery to the fellow eye. The proportion of patients in age groups is as shown (Fig. 1).

Endothelial counts were performed by taking 3 or more photographs with the Heyer-Schulte specular photomicroscope and performing fixed-frame counts from black-and-white enlargements.

\section{Results}

The scatter of cell counts with age is shown in Fig. 2, which gives an average cell count for the whole group of 3227 cells $/ \mathrm{mm}^{2}$ with a standard deviation of 554 . The mean cell count for each decade shows a gradual Correspondence to Mr M. J. Roper-Hall. decline up to the age of 50 . In the succeeding decades there is no appreciable difference between the age groups, with the mean cell counts for each age group lying within 60 cells $/ \mathrm{mm}^{2}$ of 3200 cells $/ \mathrm{mm}^{2}$ (Fig. 3).

\section{Discussion}

Irvine and Irvine ${ }^{1}$ reporting on histological preparations of normal eyes taken from subjects aged between 25 and 84 showed no evidence of variation with age. The first reports on the use of specular microscopy by Laing ${ }^{2}$ and Bourne and Kaufman ${ }^{3}$ showed a reduction of in-vivo cell count with age, and

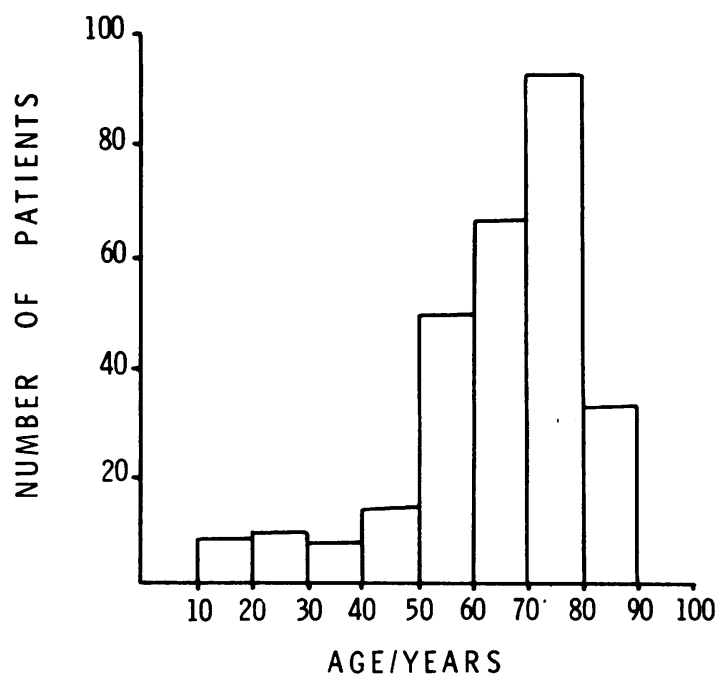

Fig. 1 Ages of patients grouped in decades. 
Fig. 2 Scatter of cell counts by age.

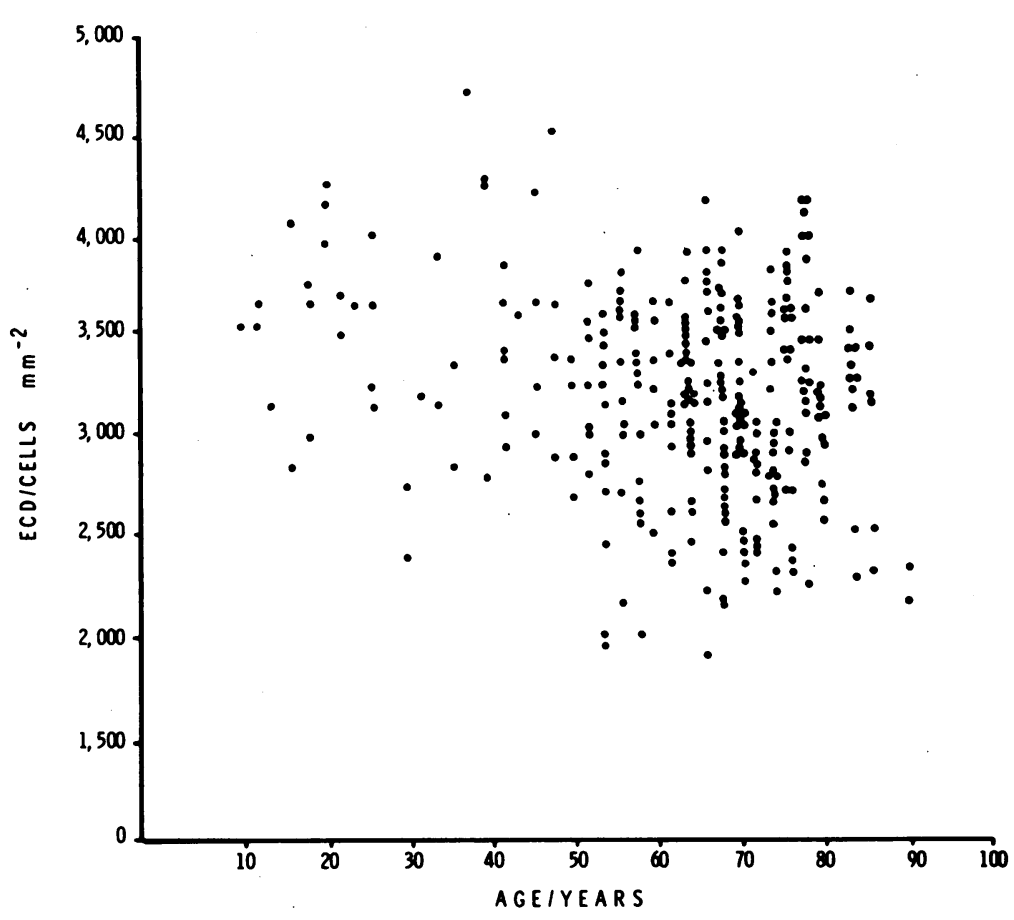

ENDOTHELIAL CELL DENSITY vS AGE a later study by Laule $e t$ al. ${ }^{4}$ demonstrated a steep decline in cell count with age up to the age of 25 , followed by a more gradual decline in subsequent years. This result extrapolated to a cell count of zero at the age of 100 years.

More recent studies, including our own, show a less significant decrease in cell count in the older age

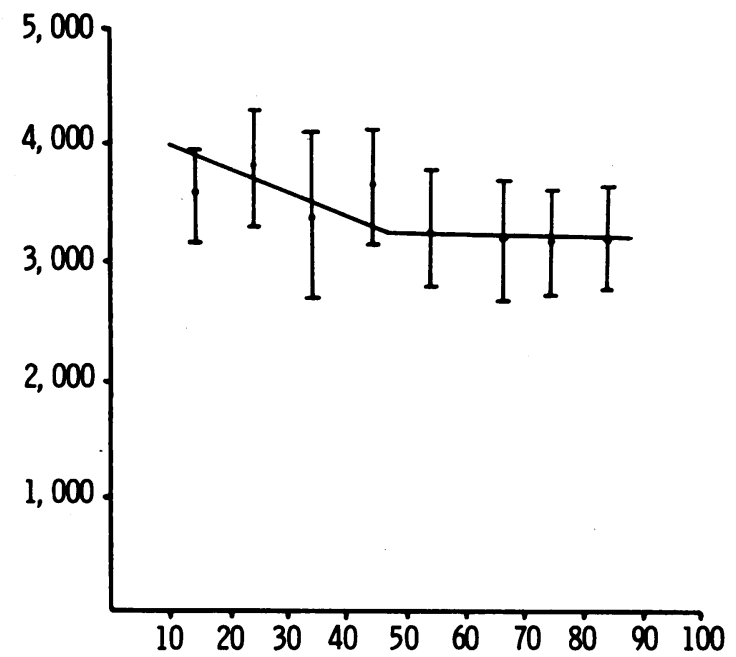

Fig. 3 Mean cell counts for each age group. groups. Sturrock et al. ${ }^{5}$ reporting on a series of 97 eyes describe an age related decrease in cell count over the entire age group, but on review of their data there appears to be a higher count in the younger age group, up to the age of 25 , followed by a nearly static average cell count in the subsequent years. Price and Barbour ${ }^{6}$ also present a series in which they describe a reduction of endothelial cell density with age. Their graph, however, shows a reduction until the fifth decade but no subsequent fall in the mean endothelial count beyond this age. Hiles et al. ${ }^{7}$ studied a group of 266 eyes in patients between the ages of 8 months and 24 years and found a drop of 500 cells $/ \mathrm{mm}^{2}$ in the first 4 years, followed by a static phase from 5 to 20 years. Our results suggest a drop in mean population cell count up to the age of 50 , which is rather later than shown in other reports. Hoffer and Kraff in an extensive study of 1523 patients between the ages of 40 and 90 show no significant drop in cell count at all.

It therefore appears that there is a reduction in cell count during early adulthood, followed by a stabilisation of the cell count throughout the remainder of life.

The metabolically very active cells have to function without replacement for many years, retaining the ability to repair defects by expansion and migration. In the course of anterior-segment surgery a proportion of cells is lost. If the endothelial cell count has already become reduced to a critical level, there is a 
risk that cells lost owing to surgical trauma will precipitate an endothelial decompensation.

Since it is not possible to assess the cell count by reference to age, it is necessary to perform specular microscopy to ascertain the cell density. There is a large population variability, but in the clinically healthy cornea it is so unusual to find a pathologically low cell count that it is questionable whether detailed specular cell studies have any place prior to routine surgical procedures. There remains the necessity for cell density estimations for research, in the study of the prevention of surgical trauma, and in the clinical management of the pathological cornea. If multiple surgery is planned, specular microscopy should be performed prior to subsequent stages. The greatest need for these studies is in the assessment of differences in cell loss during operations, either due to changes in technique or to the potential toxicity of materials introduced into the anterior chamber.

Contrary to earlier reports, recent studies show no significant endothelial cell loss beyond middle age.
Detailed specular microscopy with cell counts and morphological study is unnecessary as a routine, although its value in research studies remains considerable.

\section{References}

1 Irvine IR, Irvine IR. Variations in normal human corneal endothelium. Am J Ophthalmol 1953; 36: 1279-85.

2 Laing RA. Changes in the corneal endothelium as a function of age. Exp Eye Res 1976; 22: 487.

3 Bourne WM, Kaufman HE. Specular microscopy of human corneal endothelium in vivo. Am J Ophthalmol 1976; 81: 319-23.

4 Laule A, Cable MK, Hoffman CE, Hanna C. Endothelial cell population changes of human cornea during life. Arch Ophthalmol 1978; 96: 2031-5.

5 Sturrock GD, Sherrard ES, Rice NSC. Specular microscopy of corneal endothelium. Br J Ophthalmol 1978; 62: 809-14.

6 Price NC, Barbour DJ. Corneal endothelial cell density in twins. Br J Ophthalmol 1981; 65: 812-4.

7 Hiles DA, Biglan AW, Fetherholf EC. Central comeal endothelial cell counts in children. Am Intra-Ocular Implant Soc J 1979; 5: 292-300.

8 Hoffer KJ, Kraff MC. Normal endothelial cell count range. Ophthalmology 1980; 97: 861-6. 